\title{
Laminar Mixing in Stirred Tank Agitated by an Impeller Inclined
}

\author{
Koji Takahashi, ${ }^{1}$ Yoshiharu Sugo, ${ }^{1}$ Yasuyuki Takahata, ${ }^{1}$ \\ Hitoshi Sekine, ${ }^{2}$ and Masayuki Nakamura ${ }^{2}$ \\ ${ }^{1}$ Department of Chemistry and Chemical Engineering, Yamagata University, Yonezawa 992-8510, Japan \\ ${ }_{2}^{2}$ Process Engineering Laboratory, Corporate R\&D Department, Central Research Laboratories, DIC Co., Ltd., Sakura, \\ Chiba 285-8668, Japan
}

Correspondence should be addressed to Koji Takahashi, koji@yz.yamagata-u.ac.jp

Received 29 February 2012; Revised 18 May 2012; Accepted 18 May 2012

Academic Editor: Naoto Ohmura

Copyright () 2012 Koji Takahashi et al. This is an open access article distributed under the Creative Commons Attribution License, which permits unrestricted use, distribution, and reproduction in any medium, provided the original work is properly cited.

\begin{abstract}
The mixing performance in a vessel agitated by an impeller that inclined itself, which is considered one of the typical ways to promote mixing performance by the spatial chaotic mixing, has been investigated experimentally and numerically. The mixing time was measured by the decolorization method and it was found that the inclined impeller could reduce mixing time compared to that obtained by the vertically located impeller in laminar flow region. The effect of eccentric position of inclined impeller on mixing time was also studied and a significant reduction of mixing time was observed. To confirm the experimental results, the velocity profiles were calculated numerically and two novel numerical simulation methods were proposed.
\end{abstract}

\section{Introduction}

In recent years, many theoretical and experimental studies have been carried out for laminar chaotic mixing and have provided much beneficial information on how laminar mixing can be enhanced. However, it has also been recognized that the mixing in periodic flows is not necessarily complete, because such systems often display coexisting chaotic and nonchaotic regions. Fluids can neither penetrate nor leave these islands of unmixed fluids by regular motion. Therefore, the isolated mixing regions may become barriers to mixing.

In the pioneering studies in this field, Lamberto et al. [1] first attempted to solve this problem using time-dependent rotational velocity to enhance the mixing in a stirred tank equipped with ordinary small impellers. After that, several experimental studies have been also undertaken $[2,3]$ to demonstrate that the mixing performance can be improved markedly by increasing the chaotic degree in temporal terms. While the chaotic degree can be increased effectively by temporal terms, the approach is restricted to practical applications because of the restriction of the motor and the speed reducer machine to drive the impeller. In practice, the temporal approach has rarely been employed in the mixing industry except for washing machines.
In contrast, the chaotic degree can also be increased by spatial terms, for example, by reducing the circumferential symmetry and shifting the complexity in normal mixing equipment. While this spatial method does not improve the mixing performance as impressively as the temporal method, it places less demanding requirements on the machinery. Consequently, this approach has been widely used in industry.

The special measures employed in an agitated vessel related to spatial chaotic mixing include baffles, off-center impeller mounting, and uncircumferentially symmetrical tanks. The baffles can enhance the mixing performance remarkably and have been widely used, the off-center mounting has also been investigated thoroughly $[4,5]$ and the uncircumferentially symmetrical tanks have recently been studied [6-8]. However, the most desirable method is to know how to insert the traditional impeller into a vessel because it does not cost so much. Therefore, in the present study, the mixing performance is investigated in a vessel agitated by an impeller inclined itself, which has rarely been studied. The effectiveness of setting the impeller inclined is verified through the comparison of mixing time obtained for vertical setting impeller. Two novel numerical simulation 

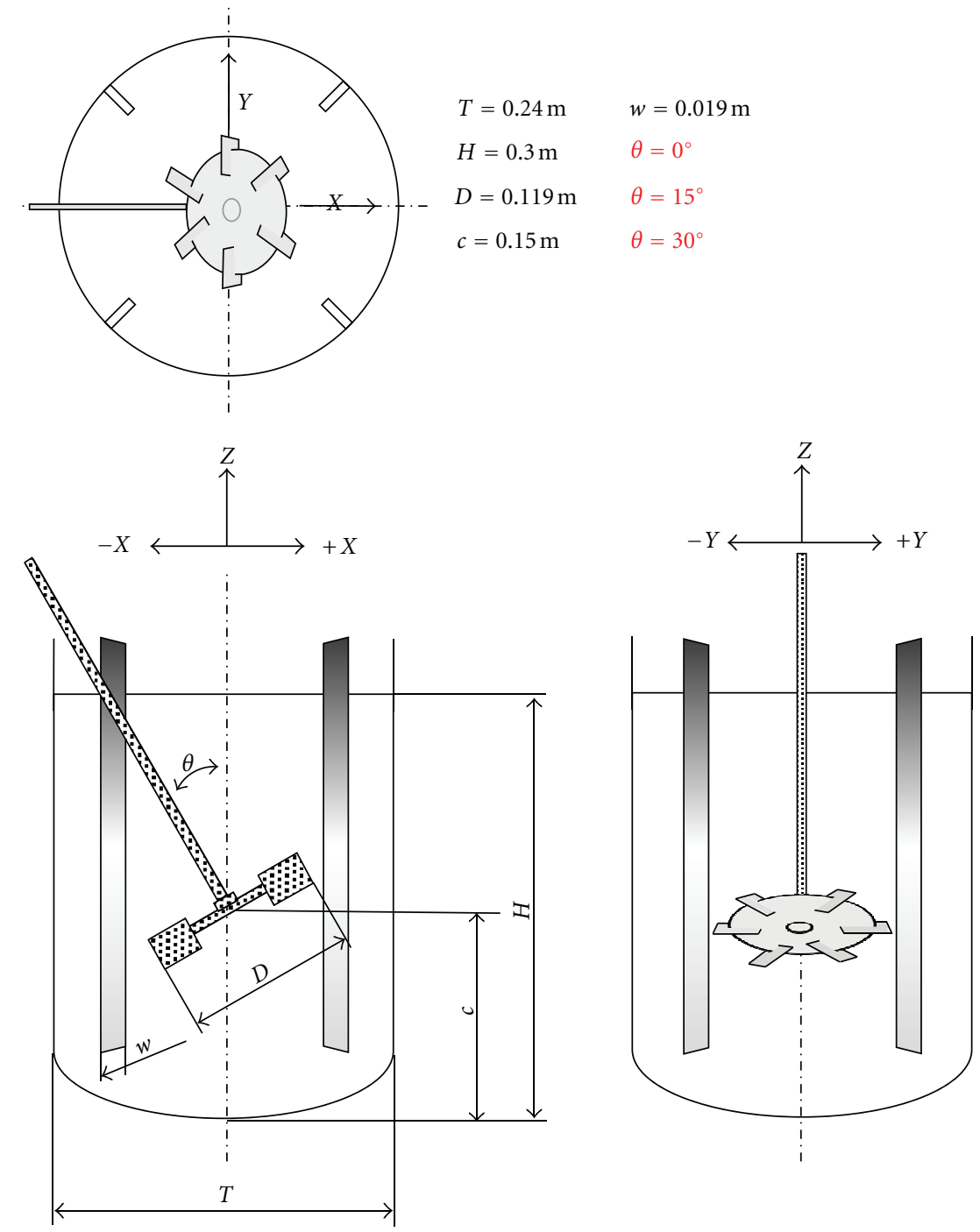

Figure 1: Experimental setup.
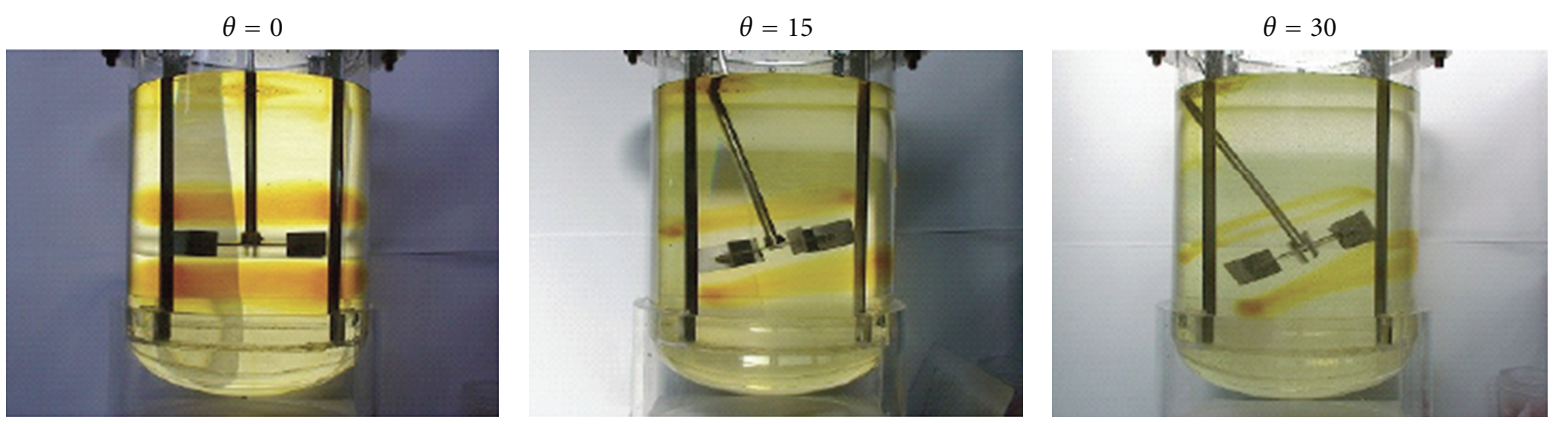

FIGURE 2: Isolated mixing regions observed $\left(50 \mathrm{~min}^{-1}, \mathrm{DT}\right), \mathrm{Re}=16.2$.

methods were proposed to confirm the experimental results obtained in this work.

\section{Mixing Time for Inclined Impeller}

2.1. Experimental. The experimental setup consists of a cylindrical vessel with four baffles and an impeller, as shown in Figure 1. The experimental conditions conducted in this work are summarized in Table 1 . The vessel was a transparent acrylic resin of $0.24 \mathrm{~m}$ inner diameter, $T$, with a liquid depth, $H$, of $1.25 T$ and has a $2: 1$ semiellipse dish shape bottom. The impellers used are a Rushton turbine (DT) and a 6 bladed pitched paddle rotated to create downward flow (PP). The impeller-to-vessel diameter ratio, $D / T$, was 0.5 and 


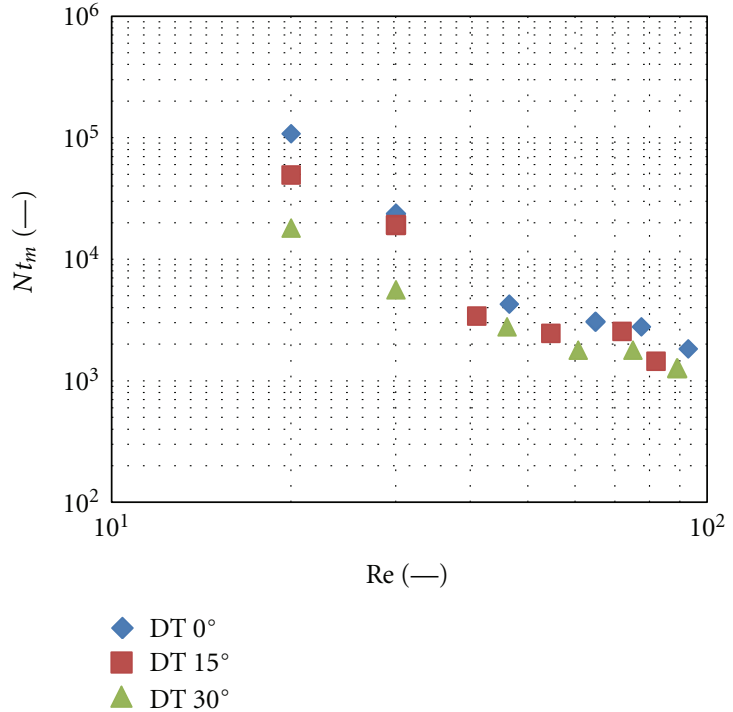

(a)

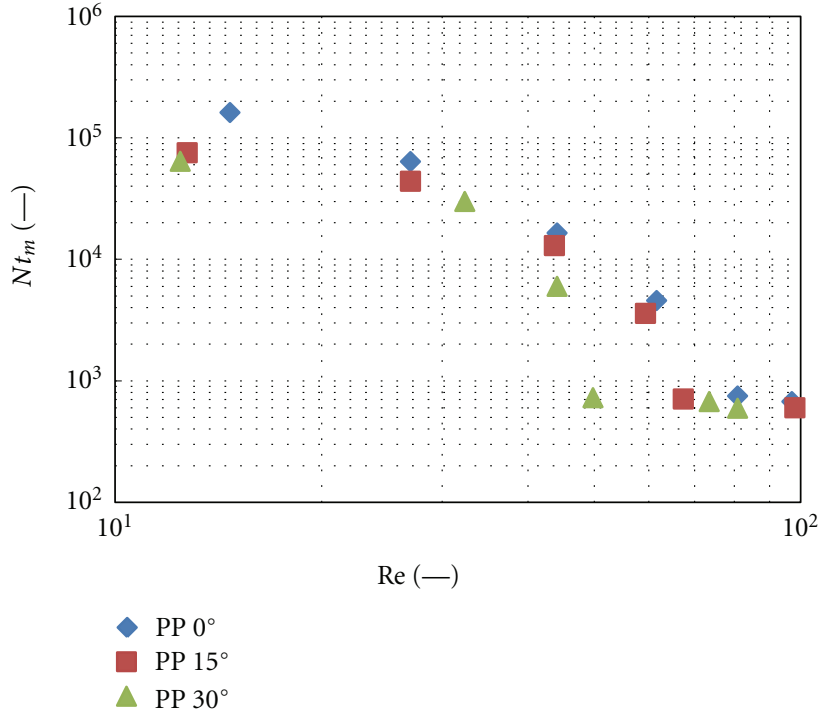

(b)

FIGURE 3: Relationship between dimensionless mixing time and Re number for disk turbine and pitched paddle.

TABLE 1: Experimental condition.

\begin{tabular}{lcc}
\hline$\mu$ & {$[\mathrm{Pa} \cdot \mathrm{s}]$} & $1.05 \sim 1.30$ \\
$N$ & {$\left[\mathrm{~min}^{-1}\right]$} & $50,100,150,200,250,300$ \\
$\theta$ & {$\left[{ }^{\circ}\right]$} & $0,15,30$ \\
$e / R$ & {$[-]$} & $0,0.2,0.25,0.33,0.5$ \\
\hline
\end{tabular}

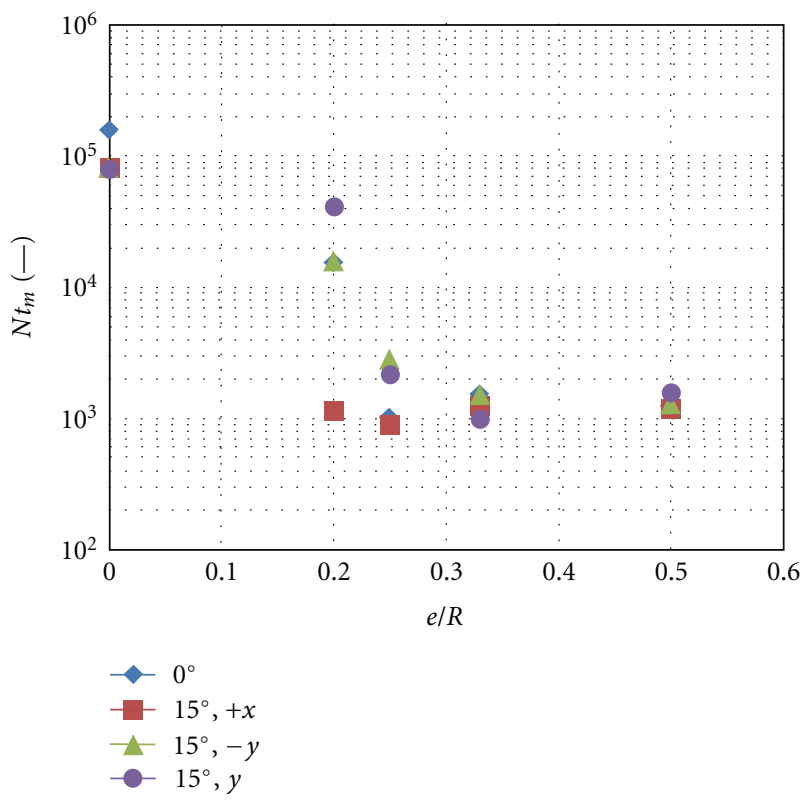

FIGURE 4: Relationship between dimensionless mixing time and eccentric ratio.

the off bottom clearance of impeller was $0.5 \mathrm{H}$. Four baffles of width $0.19 \mathrm{~m}$ were set on the vessel wall. The impeller was set vertically and inclined at 15 or 30 degrees, so as to the center of impeller is consistent with the middle of vessel. Only for
Rushton turbine set vertical and inclined 15 degree, the effect of impeller eccentricity on mixing time was also investigated. In this case, the impeller was moved to front and back of inclined side (denoted $-x$ and $+x$ ) and to the perpendicular direction (denoted $y$ ), where the distance from center of impeller to the center line of tank was changed from 0 to 0.5 of radius of vessel. Newtonian aqueous solutions of corn syrup with viscosities of about $1 \mathrm{~Pa}$ and water were used as test liquids. The mixing was carried out at the Reynolds number from 10 to 100 .

The mixing time was measured by the decoloration method adopting the reaction between iodine and thiosulfate. The optimum equivalent ratio of thiosulfate to iodine 1.4 [9] is selected to measure the mixing times. The mixing time was defined as the time required to destroy the isolated mixing regions, where the streaks observed on the vessel wall at the end of mixing were ignored when determining the mixing time.

\subsection{Mixing Time Measured}

2.2.1. Effect of Inclination of Impeller on Mixing Time. Figure 2 shows the photographs of isolated mixing regions observed after $15 \mathrm{~min}$ for different inclined angles of impeller. It is well known that the doughnut rings are formed above and below the impeller at relatively low Reynolds numbers for ordinary small impellers $[1,5]$. As expected, the doughnut rings were observed above and below the impeller not only for the vertical impeller $(\theta=0)$ but also inclined impellers $(\theta=15$ or 30$)$. However, the volume of the isolated regions reduces with an increase in the inclined angle of impeller.

The relationship between the dimensionless mixing time measured and the Reynolds number is shown in Figure 3, for impellers of different inclination. This figure shows that the 


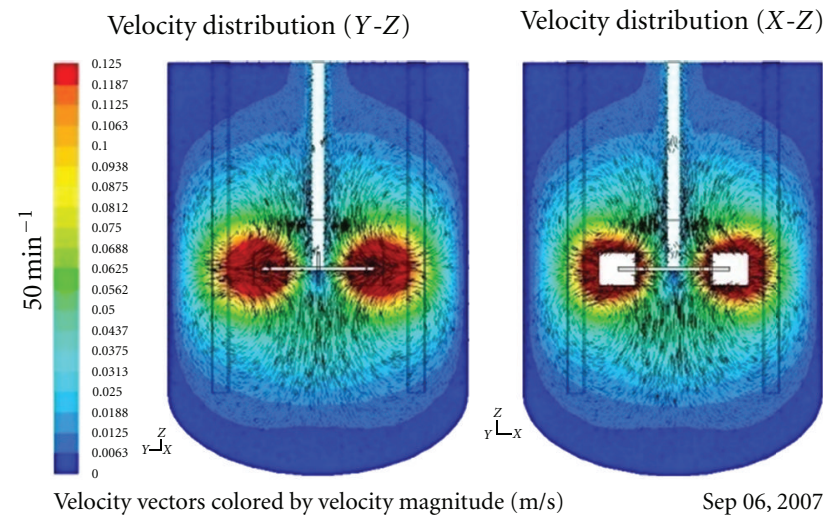

FLUENT 6.2 (3d, segregated, lam)

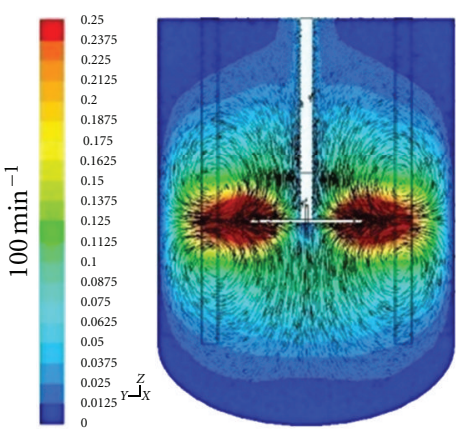

Velocity vectors colored by velocity magnitude $(\mathrm{m} / \mathrm{s})$

FLUENT 6.2 (3d, segrege
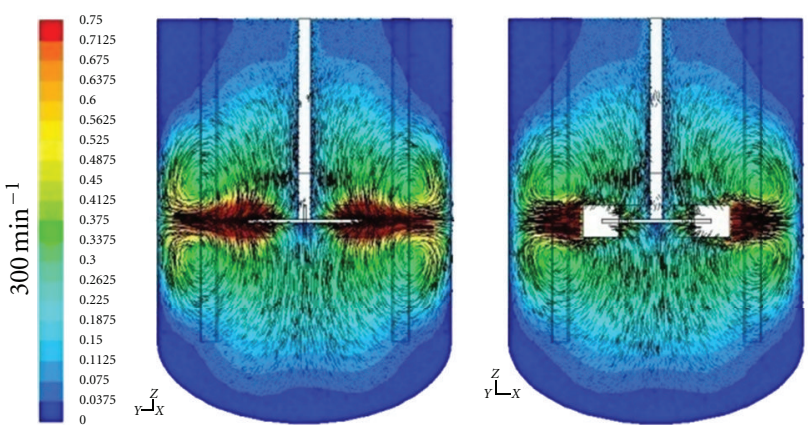

Sep 06, 2007

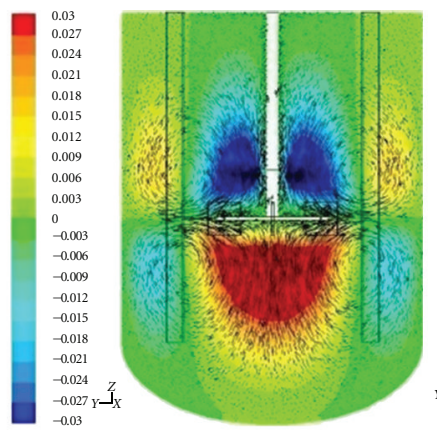

Velocity vectors colored by $Z$ velocity $(\mathrm{m} / \mathrm{s})$

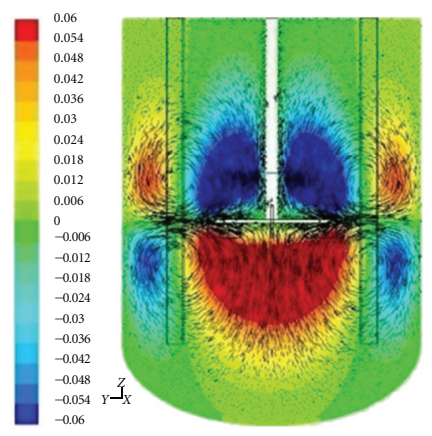

Velocity vectors colored by $Z$ velocity $(\mathrm{m} / \mathrm{s})$

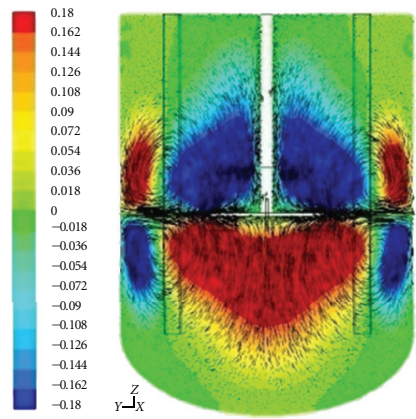

Velocity vectors colored by $Z$ velocity $(\mathrm{m} / \mathrm{s})$
Axial velocity distribution $(X-Z)$

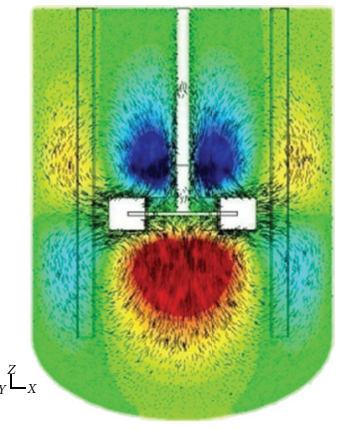

Sep 06, 2007

FLUENT 6.2 (3d, segregated, lam)

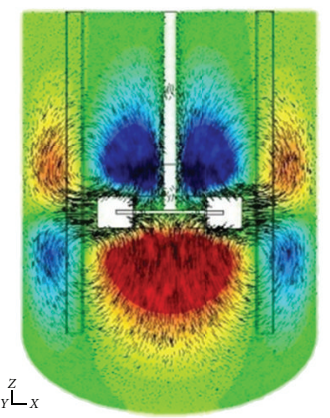

Sep 06, 2007

FLUENT 6.2 (3d, segregated, lam)

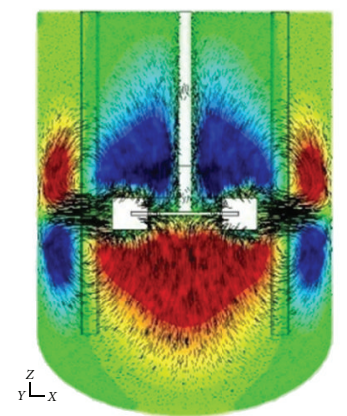

Sep 06, 2007

FLUENT 6.2 (3d, segregated, lam)

FLUENT 6.2 (3d, segregated, lam)

FIGURE 5: Three-dimensional flow velocity and axial velocity distribution (vertical located impeller). The rate vector was overlapped with each figure. The range of coloring was displayed in proportion to the rotational speed.

dimensionless mixing time decreases with an increase in Reynolds number for all impellers and with an increase in inclined angle of impeller. This result may indicate that the inclination of the impeller can promote the mixing performance in laminar flow regions. The effect of impeller inclination on mixing time is stronger for Rushton turbine than that for pitched paddle. A Rushton turbine creates radial flow to vessel wall but a pitched paddle axial one to bottom of vessel. Because of distance of impeller to vessel wall is shorter than that of impeller to bottom and the flow created by Rushton turbine is stronger than that by pitched paddle, the more effective inclination on mixing time was obtained for a Rushton turbine than for a pitched paddle.

For both impellers, the power consumption was measured but there was no effect of impeller inclination on power.

2.2.2. Effect of Eccentricity on Mixing Time. Figure 4 shows the relationship between the dimensionless mixing time measured and the Reynolds number for different eccentricities. It is clearly seen from the figure the promotion of mixing by eccentricity is more effective than that by inclination. For 


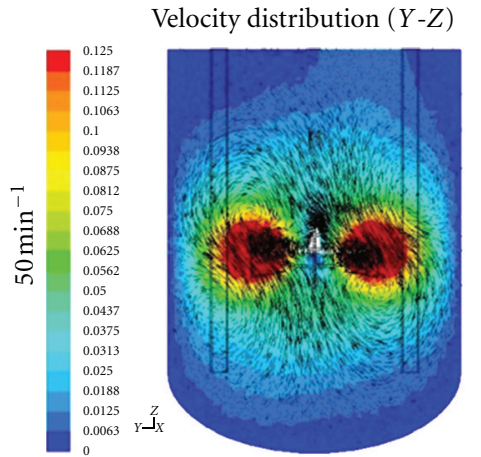

Velocity vectors colored by velocity magnitude $(\mathrm{m} / \mathrm{s})$

FLUENT 6.2 (3d, segregated,

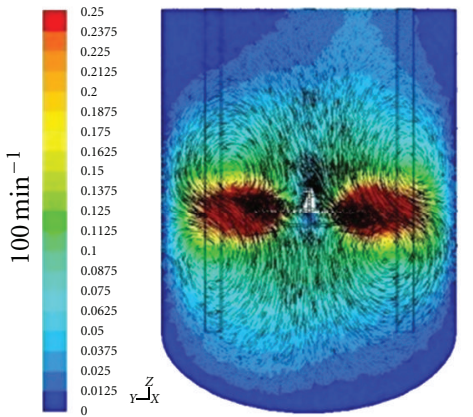

Velocity vectors colored by velocity magnitude $(\mathrm{m} / \mathrm{s})$

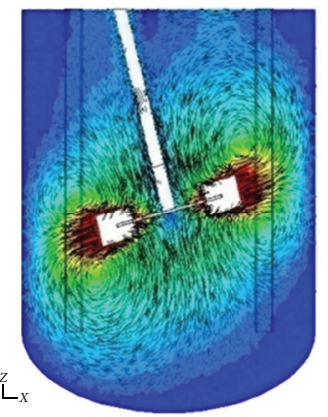

Sep 06, 2007

FLUENT 6.2 (3d, segregated, lam)

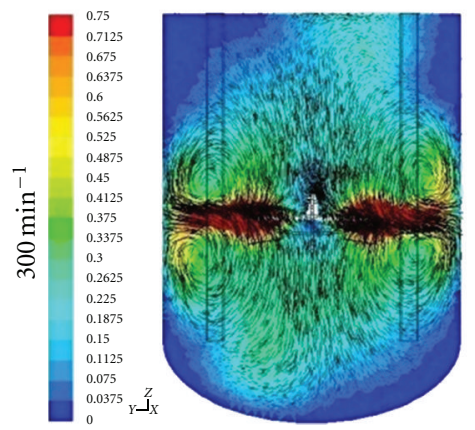

Velocity vectors colored by velocity magnitude $(\mathrm{m} / \mathrm{s})$

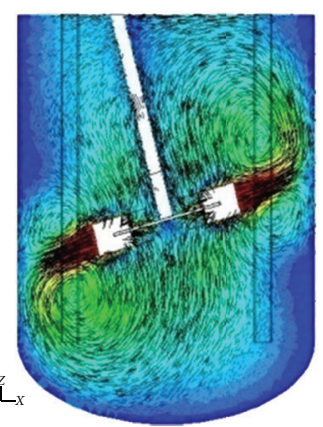

Sep 06, 2007

FLUENT 6.2 (3d, segregated, lam)
Axial velocity distribution $(Y-Z)$

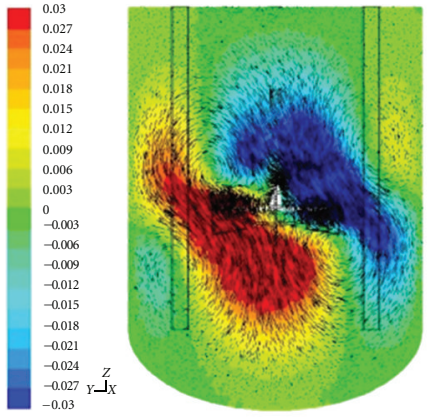

Velocity vectors colored by $Z$ velocity $(\mathrm{m} / \mathrm{s})$

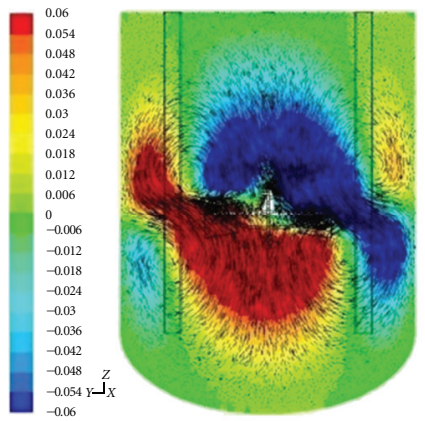

Velocity vectors colored by $Z$ velocity $(\mathrm{m} / \mathrm{s})$

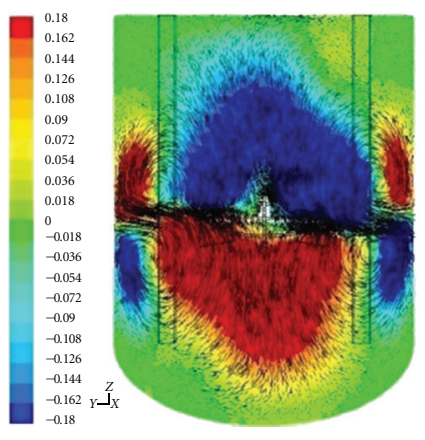

Velocity vectors colored by $Z$ velocity $(\mathrm{m} / \mathrm{s})$
Axial velocity distribution $(X-Z)$

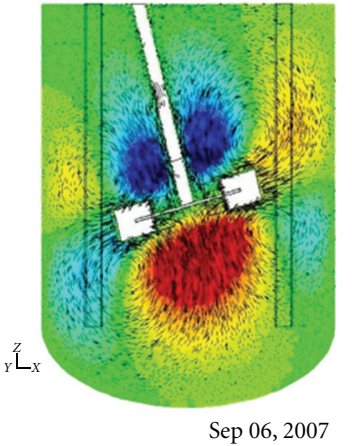

FLUENT 6.2 (3d, segregated, lam)

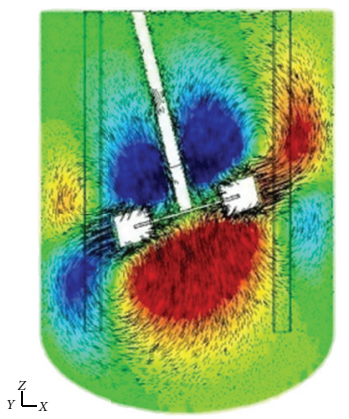

Sep 06, 2007

FLUENT 6.2 (3d, segregated, lam)

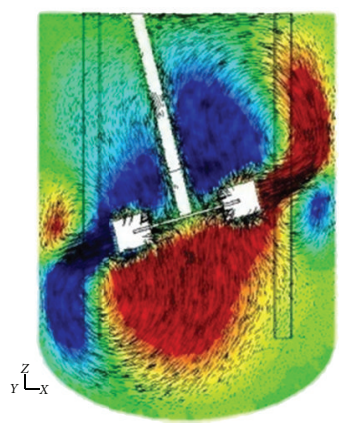

Sep 06, 2007

FLUENT 6.2 (3d, segregated, lam)

Figure 6: Three-dimensional flow velocity and axial velocity distribution (impeller inclined at $15^{\circ}$ ). The rate vector was overlapped with each figure. The range of coloring was displayed in proportion to the rotational speed.

vertical impeller, the mixing time decreases gradually with an increase in eccentricity as reported by Takahashi et al. [5]. For impeller inclined 15 degree moved to front of inclined side (denoted $-X$ ) and the perpendicular direction (denoted $Y$ ), the mixing times change with almost the same with those of vertical impeller. On the other hand, for impeller inclined moved to back of inclined side decreases drastically with a small change of eccentricity and then become constant at the eccentricity more than 0.25 .

\section{Flow Simulation}

3.1. Simulation Method. In literature, there is no data on velocity profiles in a vessel agitated by an inclined impeller.
Thus, in order to get the information of the flow field in a vessel agitated by an inclined impeller, the flow simulation was carried out. The impeller simulated is a Rushton turbine because the more effective inclination on mixing was obtained for Rushton turbine than for pitched paddle, as is indicated in the previous section.

The geometries of mixing vessel and impeller provided for the numerical calculations are similar to those used in the experiment. The velocity profiles were calculated for the impeller inclined at 15 and 30 degrees to the vertical axis. For comparison, the velocity profiles created by vertically located impeller in a vertical vessel were also calculated. The simulation was conducted at the rotational speeds of 50,100, and 


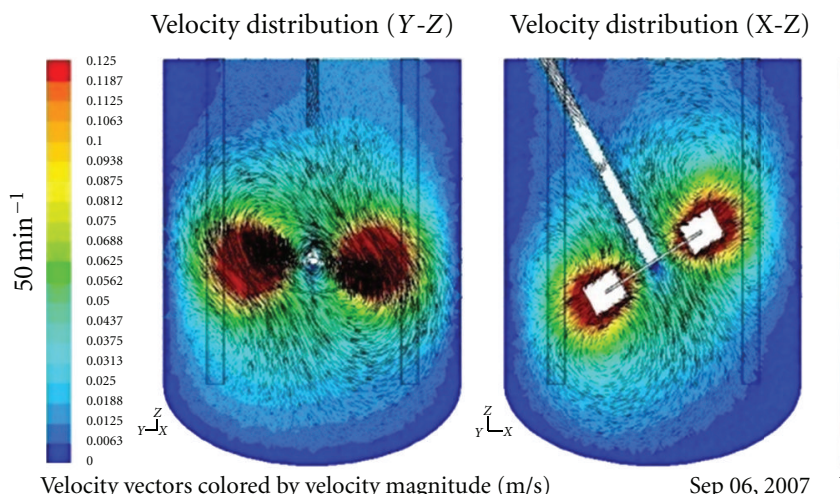

FLUENT 6.2 (3d, segregated, lam)

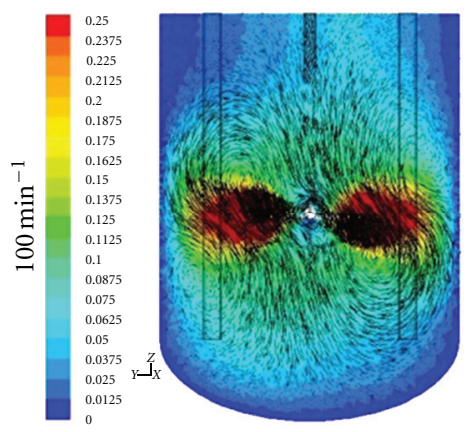

Velocity vectors colored by velocity magnitude $(\mathrm{m} / \mathrm{s})$

FLUENT 6.2 (3d, segregated, lam)
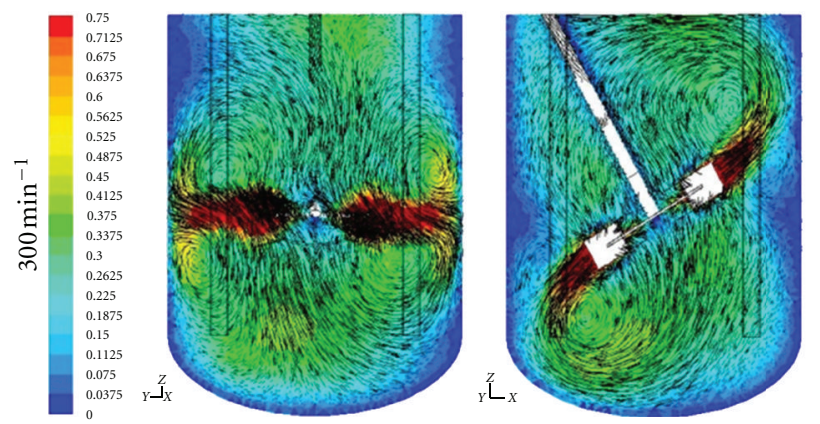

Velocity vectors colored by velocity magnitude $(\mathrm{m} / \mathrm{s})$

FLUENT 6.2 (3d, segregated, lam)

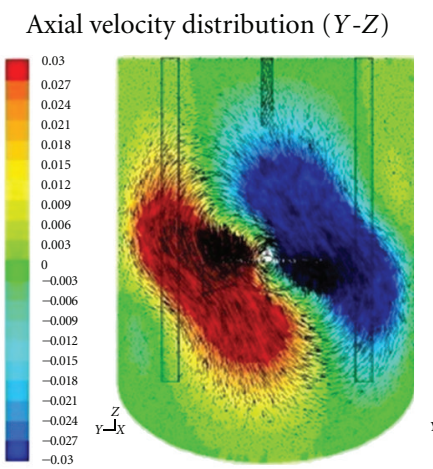

Velocity vectors colored by $Z$ velocity $(\mathrm{m} / \mathrm{s})$

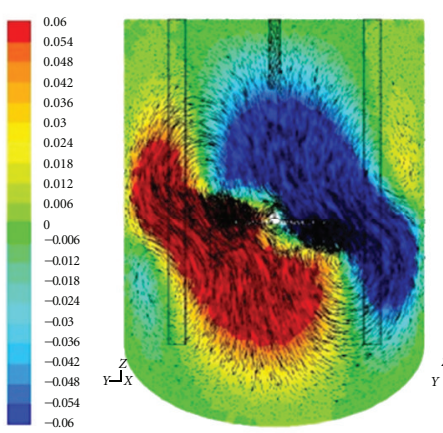

Velocity vectors colored by $Z$ velocity $(\mathrm{m} / \mathrm{s})$

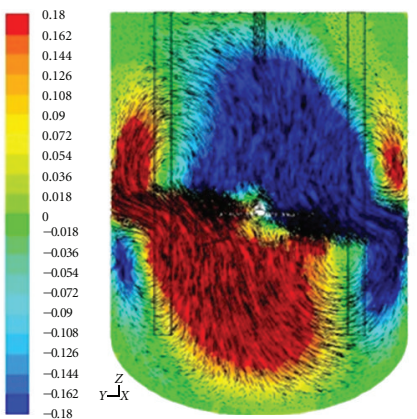

Velocity vectors colored by $Z$ velocity $(\mathrm{m} / \mathrm{s})$
Axial velocity distribution $(X-Z)$

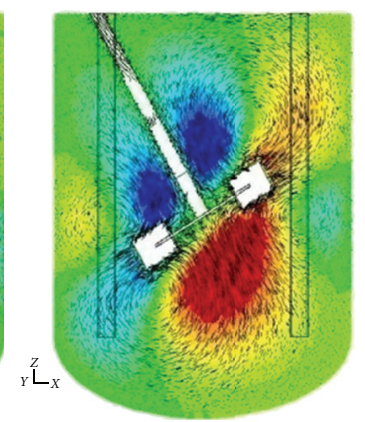

Sep 06, 2007

FLUENT 6.2 (3d, segregated, lam)

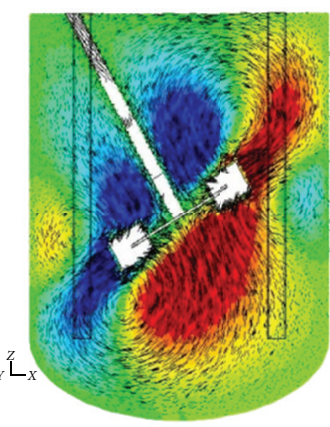

Sep 06, 2007

FLUENT 6.2 (3d, segregated, lam)

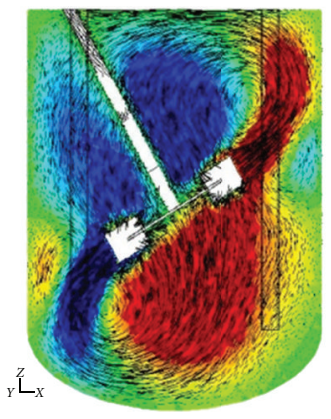

Sep 06, 2007

FLUENT 6.2 (3d, segregated, lam)

FIgURE 7: Three-dimensional flow velocity and axial velocity distribution (impeller inclined at $30^{\circ}$ ). The rate vector was overlapped with each figure. The range of coloring was displayed in proportion to the rotational speed.

$300 \mathrm{rpm}$, which correspond to the Reynolds numbers of 16.5, 33.0, and 99.0, respectively. The viscosity and density of liquid was set at $1 \mathrm{Pas}$ and $1400 \mathrm{~kg} / \mathrm{m}^{3}$. The fluid flow is solved using the three-dimensional finite-volume method software FLUENT developed by Fluent Inc. in the USA. A steady flow field on a rotating frame of reference fixed on the impeller is adopted.

3.2. Flow Field Simulated. Figures 5, 6, and 7 show the threedimensional flow velocity distributions and the axial ones, those are the most important components to consider for the mixing, calculated in the $Y-Z$ and $X-Z$ cross sections (see Figure 1), where $Y-Z$ cross section is perpendicular to and $X-Z$ one parallel to impeller shaft. There is no difference in velocity distribution in $Y-Z$ and $X-Z$ cross sections for vertical impeller, regardless whether it is threedimensional flow velocity or axial velocity distributions. For inclined impellers, the three-dimensional flow velocity and the axial velocity distributions obtained for $Y-Z$ and $X-Z$ cross section are completely different from each other. It is clearly seen from these figures, with an increase in inclined angle of impeller and with an increase in rotational speed, the velocity becomes high and the area of high velocity regions increases, especially near free surface and bottom of vessel. The simulated results may indicate the higher the mixing performance, the larger the inclined angle of impeller.

\section{Estimation of Mixing Performance by Numerical Simulation}

In order to evaluate the dispersive mixing performance, two unique simulation methods were proposed based on the flow simulation results obtained above. One is the simulation of 

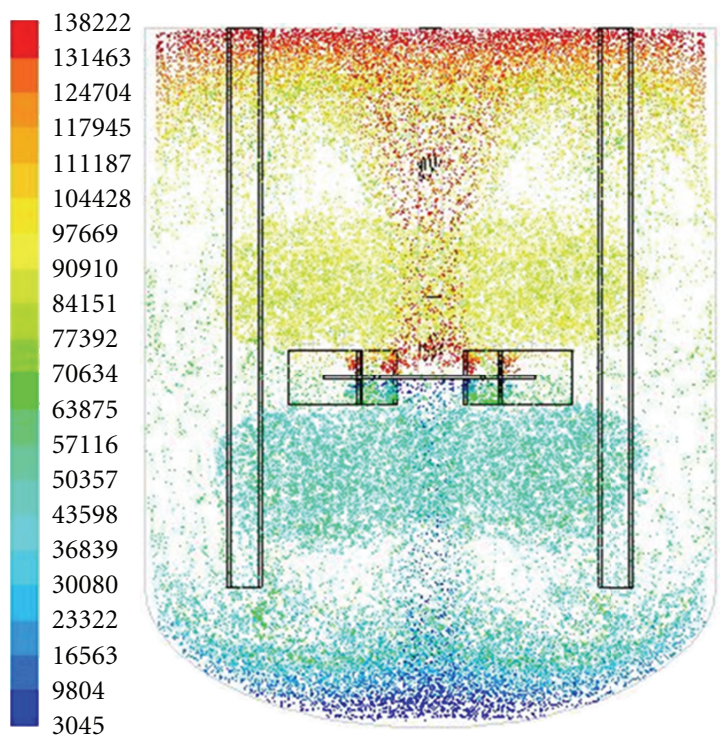

(a)
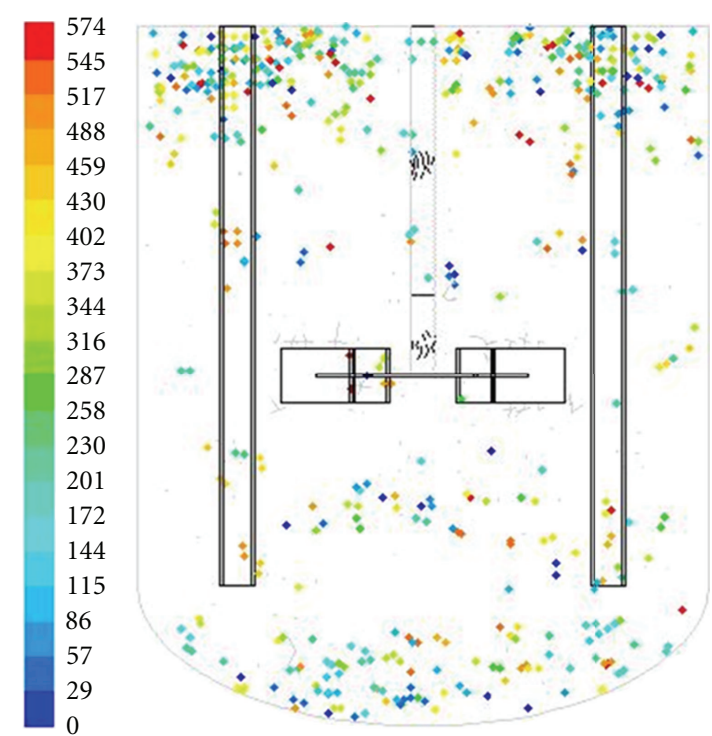

(b)

FIgURE 8: Simulation result of particle dispersion $\left(\theta=0^{\circ}\right)$.
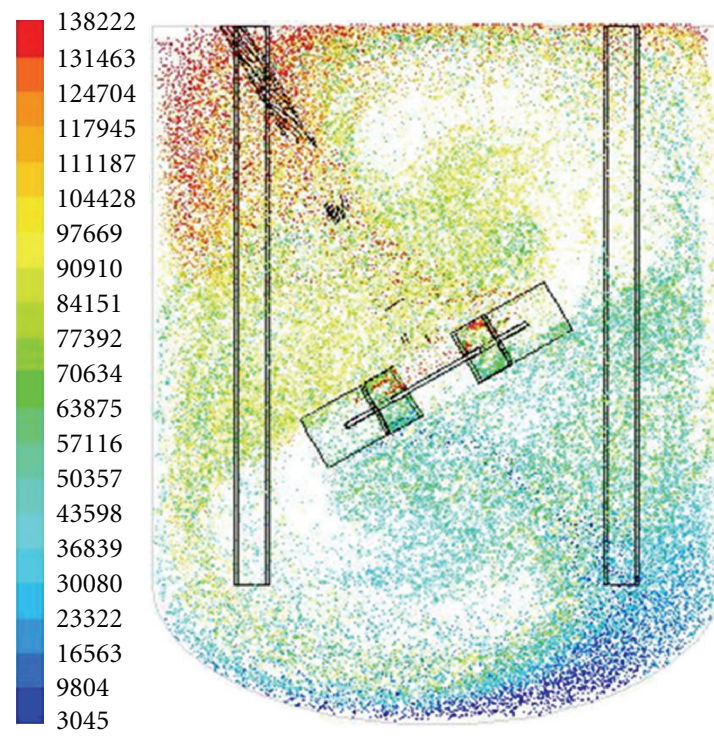

(a)
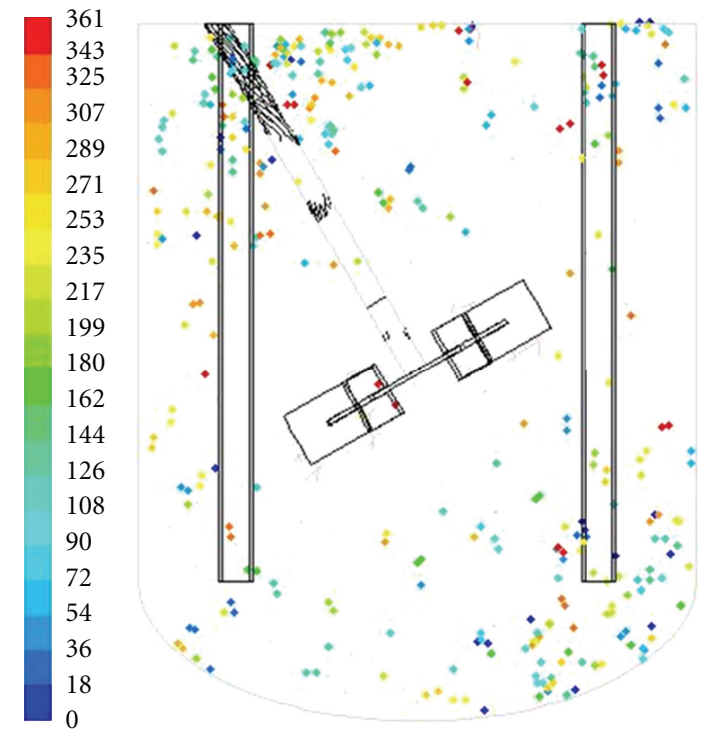

(b)

FIgURE 9: Simulation result of particle dispersion $\left(\theta=30^{\circ}\right)$.

particles dispersion and another is that of mixing of two miscible liquids.

4.1. Particle Dispersion. To quantify the mixing performance, the dispersion of particles is calculated for the vertical and 30 degree inclined impeller. If the flow is dispersive, the neighboring particles will be separated from each other. Based on this concept, the analysis was carried out according to the following procedure.

(1) Initially, the particles were positioned at all intersections of the $X, Y$, and $Z$ lines at every $5 \mathrm{~mm}$ intervals throughout the tank, where the particles are supposed to have the same density with the liquid.

(2) The movement of the particles was calculated according to the flow generated by impeller for 30 seconds after the start of agitation, where the particles are assumed to move exactly with liquid.

(3) For six particles placed adjacently from the marked particle ( 2 particles in each coordinate), the distances from the marked particle were calculated. If the distances become longer more than $7 \mathrm{~mm}$ (original distance of $5 \mathrm{~mm}+$ another $2 \mathrm{~mm}$ ), the particles were removed from the image. 

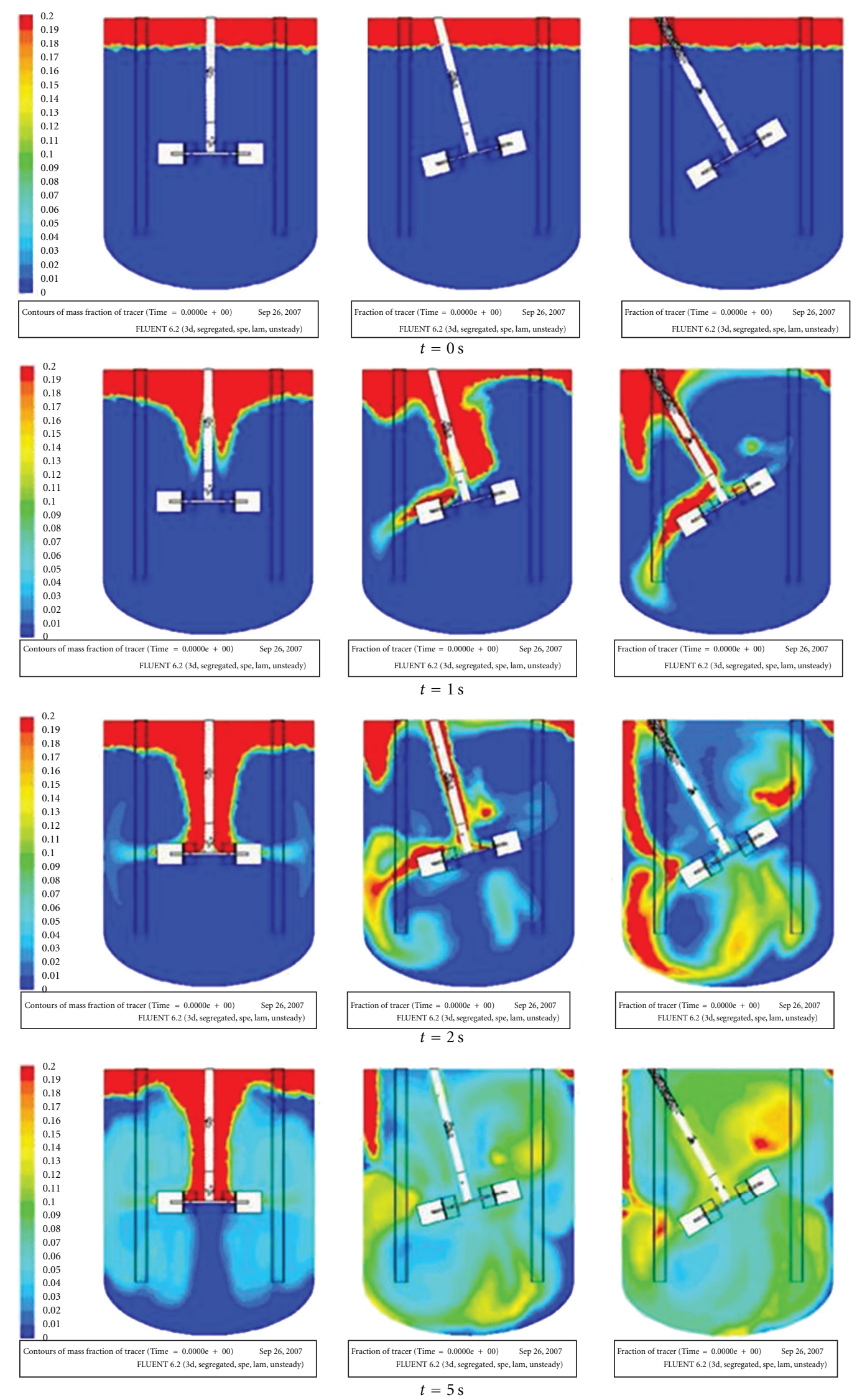

Figure 10: Continued. 

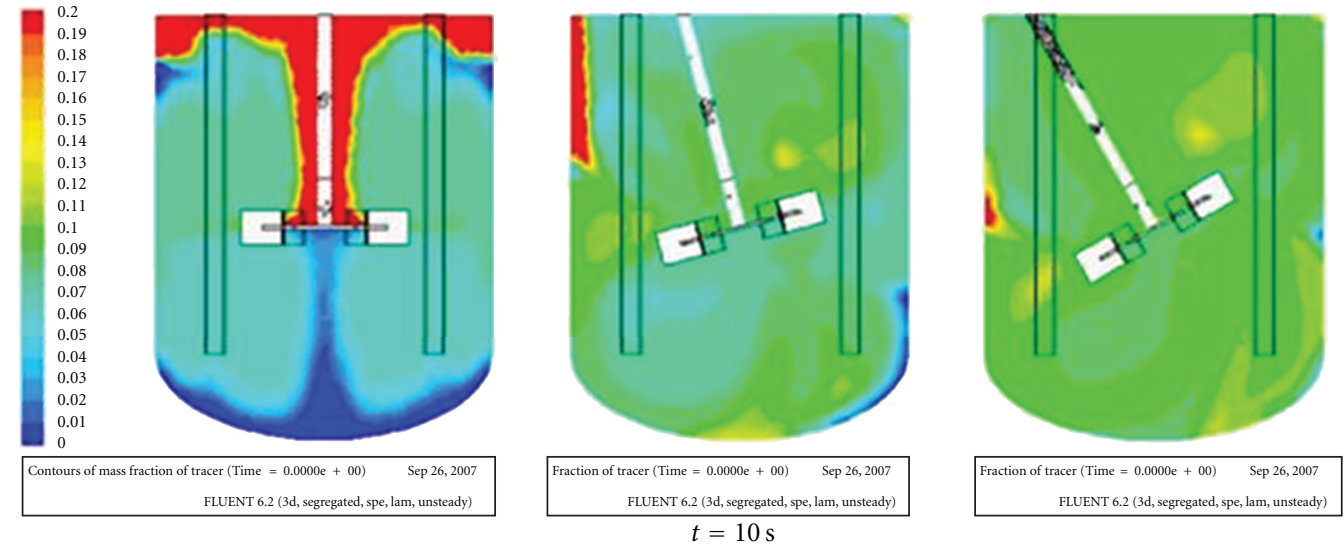

FIGURE 10: Simulation result of mixing of two miscible liquids.

(4) In order to get a clear image, $99 \%$ of remaining particle were also removed at random from the image.

(5) The number of remaining particles on the image was counted for both conditions.

The results of the simulations are shown in Figures 8 and 9. In these figures, the colors indicate the initial positions of the particles in axial direction, where red indicates top position and blue bottom one. Figures 8(a) and 9(a) are the results after removing the particles whose distances become longer than $7 \mathrm{~mm}$ and Figures 8(b) and 9(b) ones after eliminating 99\% particles. In Figures 8(b) and 9(b), 574 particles remained in the vertical impeller condition, and 367 particles remained in the inclined impeller condition. The smaller number of particle, the higher the ability particle dispersion. Thus, it is confirmed that the inclined impeller condition exhibited a high dispersion ability.

4.2. Mixing of Two Miscible Liquids. Based on the flow simulation, the mixing process of two miscible liquids was simulated for the vertical and inclined 15 and 30 degree impellers. Two miscible liquids of same viscosity and density were set in a vessel: blue one $90 \%$ lower and red one $10 \%$ upper in a vessel. The calculation was conducted for 10 seconds.

The results are shown in Figure 10. It is clearly seen from the figure, with an increase in inclined angle, the mixing proceeds quickly throughout vessel. Especially, it should be noted that the entrainment of liquid near free surface has easily taken place for inclined impellers. In the process industries, solids lighter than liquid are commonly required to be dispersed into liquid [10]. For such purposes, the inclined impeller may be adequate to use.

\section{Conclusions}

The effects of impeller inclination angle on spatial chaotic mixing were investigated experimentally and numerically. The mixing pattern was observed and the mixing time was measured using the decoloration method. Agitation by an inclined impeller creates an effective flow pattern for mixing by reducing the size of the isolated mixing regions in the vessel. The results of the numerical simulations showed a complex flow and high ability of particle dispersion in the inclined impeller condition. Therefore, the flow control of the inclined impeller agitation introduced in this paper should be applicable to a wide range of processes.

\section{Nomenclature}

c: Off-bottom clearance of impeller [m]

$D$ : Diameter of impeller [m]

$e:$ Distance from shaft to center line of tank [m]

$H$ : Liquid depth [m]

$N$ : Impeller speed $\left[\mathrm{s}^{-1}\right]$

$R:$ Radius of tank [m]

Re: Reynolds number [-]

$T$ : Tank diameter $[\mathrm{m}]$

$t_{m}$ : Mixing time $[\mathrm{s}]$

$w$ : Baffle width $[\mathrm{m}]$

$\mu$ : Liquid viscosity [Pa s]

$\rho: \quad$ Liquid density $\left[\mathrm{m} \mathrm{s}^{-3}\right]$

$\theta$ : Inclined angle of impeller [-].

\section{References}

[1] D. J. Lamberto, F. J. Muzzio, P. D. Swanson, and A. L. Tonkovich, "Using time-dependent RPM to enhance mixing in stirred vessels," Chemical Engineering Science, vol. 51, no. 5, pp. 733-741, 1996.

[2] T. Nomura, T. Uchida, and K. Takahashi, "Enhancement of mixing by unsteady agitation of an impeller in an agitated vessel," Journal of Chemical Engineering of Japan, vol. 30, no. 5, pp. 875-879, 1997.

[3] W. G. Yao, H. Sato, K. Takahashi, and K. Koyama, "Mixing performance experiments in impeller stirred tanks subjected to unsteady rotational speeds," Chemical Engineering Science, vol. 53, no. 17, pp. 3031-3040, 1998.

[4] J. Karcz, M. Cudak, and J. Szoplik, "Stirring of a liquid in a stirred tank with an eccentrically located impeller," Chemical Engineering Science, vol. 60, no. 8-9, pp. 2369-2380, 2005. 
[5] K. Takahashi, D. Shigihara, and Y. Takahata, "Laminar mixing in eccentric stirred tank with different bottoms," Journal of Chemical Engineering of Japan, vol. 44, pp. 931-935, 2011.

[6] H. Xiao and K. Takahashi, "Mixing characteristics in the horizontal non-baffled stirred vessel in low viscosity fluid," Journal of Chemical Engineering of Japan, vol. 40, no. 8, pp. 679-683, 2007.

[7] K. Takahashi, Y. Takahata, T. Imai, and K. Shisai, "Development of nobel equipment to produce bio-diesel fuel," Kagaku Kogaku Ronbunshu, vol. 37, pp. 852-858, 2011.

[8] T. Yang and K. Takahashi, "Effect of impeller blade angle on power consumption and flow pattern in horizontal stirred vessel," Journal of Chemical Engineering of Japan, vol. 43, no. 8, pp. 635-640, 2010.

[9] K. Takahashi, Y. Takahata, T. Yokota, and H. Konno, "Mixing of two miscible highly viscous newtonian liquids in a helical ribbon agitator," Journal of Chemical Engineering of Japan, vol. 18, no. 2, pp. 159-162, 1985.

[10] K. Takahashi and S. I. Sasaki, "Complete drawdown and dispersion of floating solids in agitated vessel equipped with ordinary impellers," Journal of Chemical Engineering of Japan, vol. 32, no. 1, pp. 40-44, 1999. 

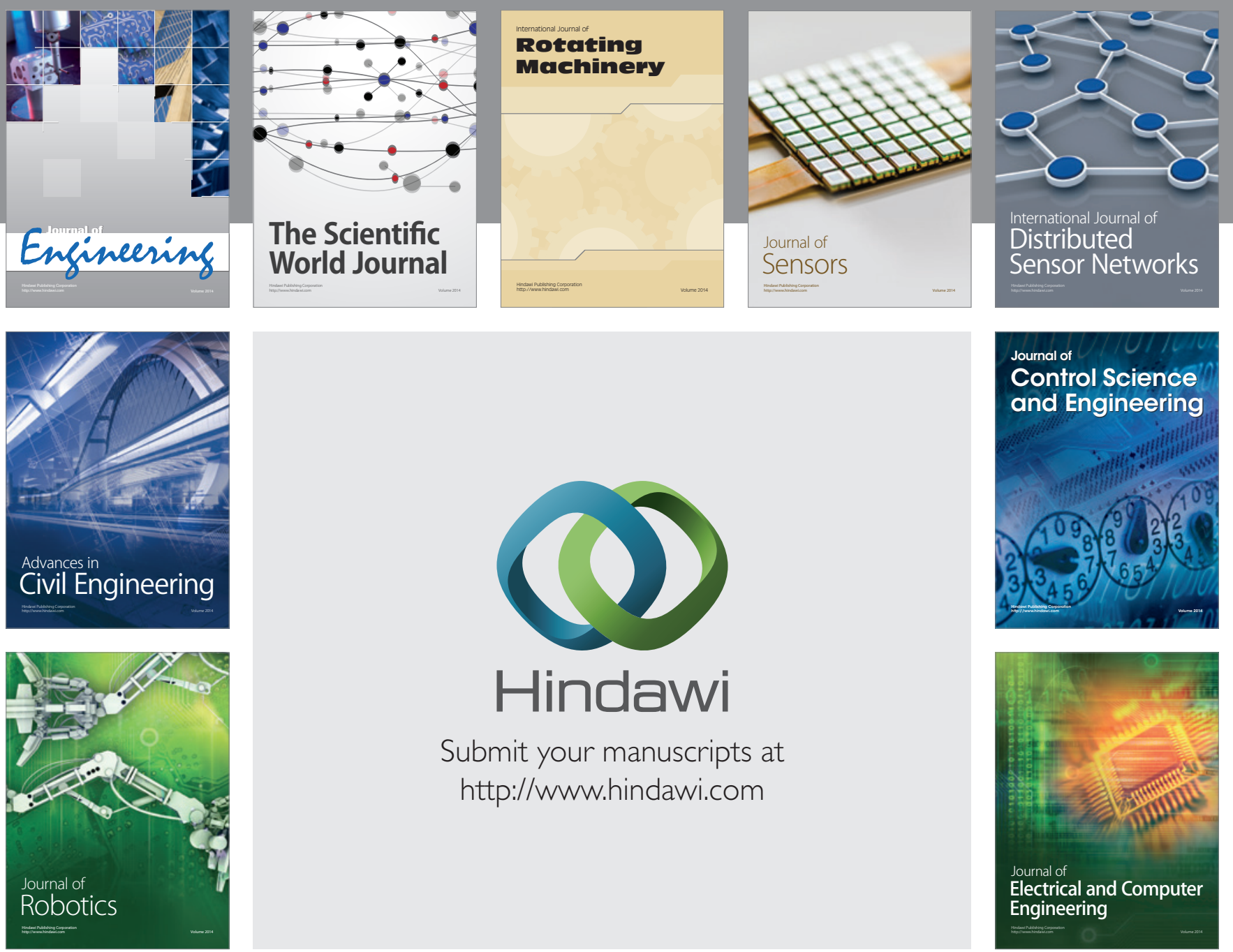

Submit your manuscripts at

http://www.hindawi.com
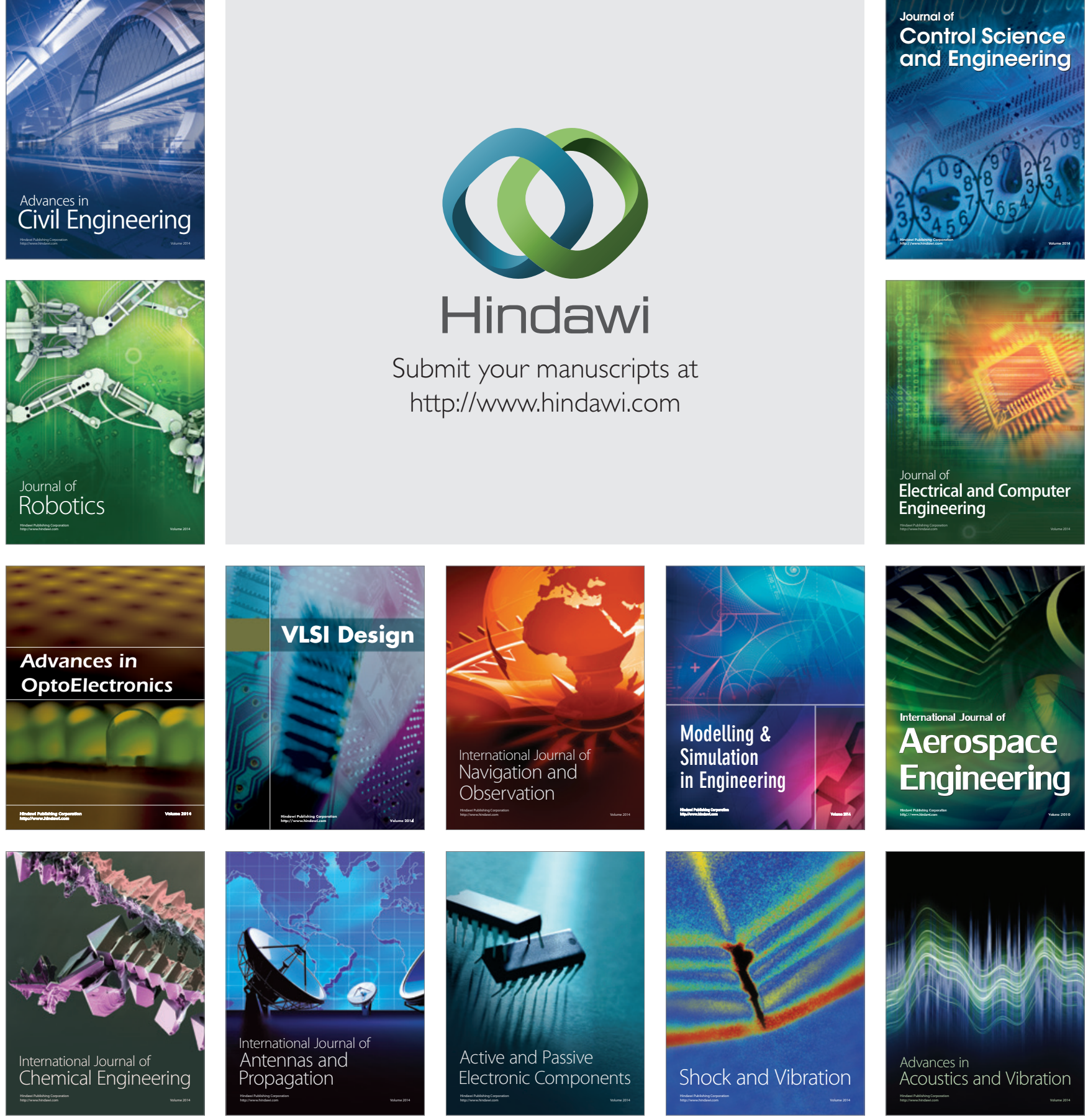